\title{
Coordination between participants in the BIM- based renovation of street engineering networks
}

\author{
Pavel Shatalov ${ }^{1, *}$, Andrey Eremin ${ }^{1}$, Elena Sharapova ${ }^{1}$, Anna Vorotyntseva $^{1}$ \\ ${ }^{1}$ Voronezh State Technical University, Moscow Avenue, 14, Voronezh, 394026, Russia
}

\begin{abstract}
The paper discusses the solution to the problem of communication between the parties interested in the implementation of projects for the renovation of street engineering networks in the context of the construction of "Smart cities in Russia" through the use of BIM technologies, including the program " $60+$ ". The prospects and difficulties arising in the implementation of BIM in the Russian Federation are considered. The term of BIM-based renovation of street engineering networks (BbRSEN) is proposed. An effective digital data environment for conducting BbRSEN is presented, the main participants, the emerging flows of information exchange between them, and the role of the state are identified. A universal step-by-step procedure for the implementation of BbRSEN and the possibility of its subsequent cyclic use throughout the city has been developed. The result of BbRSEN is not only a comprehensive cost-effective replacement of engineering infrastructure, but also the creation of "Smart grids" that become the basis for the future development of a "Smart city" in which all engineering networks are designed as a single complex of urban infrastructure with the calculation of the efficiency of the entire life cycle. The introduction of the attribute in the digital model, which characterizes the wear of the networks, is substantiated for the harmonization of the repair cycles of the road surface and all underground communications under it.
\end{abstract}

\section{Introduction}

The state and general trend of the state of communal infrastructure in the Russian Federation shows the need for large-scale renovation works. A justified reaction to this was the development of a Project for the modernization of communal infrastructure with a depreciation rate of over 60 (program "60+") and its launch in 2020 in five regions of the Russian Federation with the aim of modernizing the communal infrastructure of regions with the highest degree of deterioration. The first of them will be implemented in the city of Orsk, Orenburg Region, with a budget of over 400 million rubles. Do not forget about the regions where, on formal grounds (only a couple of percent of wear was missing), no support from the federal budget is provided, they should only be managed by the regional budget and funds from private infrastructure organizations. The problem is especially

\footnotetext{
${ }^{*}$ Corresponding author: shatalovpavel@mail.ru
} 
relevant for Tatarstan, in order to prevent a "communal catastrophe", where, according to statistics, heating networks are worn out on average by $54.3 \%$, water supply and sanitation by $53.6 \%$. The studies carried out show that aging processes with significant wear become "catastrophic", and it is they that begin to play a prevailing, decisive role in a sharp increase in the failure rate of urban infrastructure facilities. In practice, this suggests that any measures to restore the facility's performance become clearly inappropriate [1] and require replacement.

When choosing regions, the wear of intra-quarter and main engineering networks is calculated. For financing, subsidies for capital investments and for compensation of interest rates on loans, property tax incentives or other reasonable methods of financial support are provided. The purpose of the project is aimed at updating the local networks of heat and water supply, sewerage. Gas supply networks, in some places, need to be restored, but their general condition is much better, which is associated with the increased danger of the physical properties of the transported substance, as well as the better financial condition of gas distribution organizations.

The Russian Federation strives to move onto the path of creating "Smart cities". The project of the Standard for the "Smart City of Russia" is one of the first steps towards the formation and implementation of effective projects in the field of informatization and automation of municipal services, simplifying the introduction of new digital technologies in the urban environment. The goal of the path is to improve the quality of life and the efficiency of services for citizens through the introduction of the latest digital technologies. It is worth noting the following requirements of this standard, which provide for:

- overall improvement of infrastructure efficiency,

- data analysis of infrastructure organizations (in particular, housing and communal services and fuel and energy complex),

- creation of the Digital Twin - a unified digital database of the city,

- ensuring the relevance and machine-readable format of urban planning documents,

- approval and implementation of uniform formats and protocols for data exchange,

- digitization of infrastructure facilities,

- planning investment and production programs using intelligent systems for predicting accidents.

It can be noted that the main focus is on improving the efficiency of the operational characteristics of the existing engineering infrastructure of the city. Popov E.V. and Semyachkov K.A suggested that a smart city involves integrated information management, which creates value through the use of advanced technologies for search, access, transmission and processing of data, and also distinguish levels characterizing the degree of its development: the first is the urban level infrastructure, and the fourth is the level of information and communication infrastructure that unites the urban economy into a single information space [2], which confirms the relevance and importance of digitalization and communication problems in the management of smart cities.

Most developed and developing countries follow this path. Their experience shows the economic efficiency of this development, the success of Singapore with its Virtual Singapore project should be noted. A distinctive feature of the Russian way is the existing high percentage of network deterioration, in contrast to the situation with which the majority of foreign countries began to create "smart cities".

One of the challenges of digital development is the need to process large amounts of data from various sources. Regular collection of data from each owner and user of engineering infrastructure, processing and making reasonable management decisions based on the opinions of all interested parties, as well as their return to management services and departments. All this creates the great difficulties in the interaction of various services and departments, and as the amount of transmitted information increases (and during the 
implementation of the smart city project, the increase will be multiple), the existing system will "drown" in this flow. All this confirms the relevance of the goal of finding effective ways of communication between all parties interested in the implementation of the project "Smart Cities of Russia", in large-scale projects to modernize worn-out engineering infrastructure of cities, the $60+$ program, in the renovation of residential buildings and industrial areas in the center large cities of the Russian Federation, as well as during the renovation of street engineering networks. A prerequisite for the found solution should be economic efficiency, which is especially relevant in the context of a decrease in GDP and a decrease in the state's financial reserves due to the ongoing pandemic.

\section{Methods}

In our work, the object of the study was land plots in large cities with a complex of utilities that have significant average wear and tear, and the subject of the study was the emerging communications between the parties interested in the implementation of projects for the renovation of street utilities in the context of the construction of "Smart Cities in Russia".

With such a large percentage of wear of almost all engineering networks of the microdistrict in the city, it is rational to carry out their restoration on the basis of an innovative approach. An innovative approach is based on correlating the remaining service life of engineering networks with the average life of buildings in the considered element of the planning structure (cluster). The procedure is detailed on the basis of the gas pipeline network in the city and is applicable to other engineering networks [3]. Further research showed that the renovation of street engineering networks is applicable to the renewal of engineering networks by all organizations operating underground linear facilities, the wear of which is more than $40 \%$. The main economic effect is achieved by the interaction of the services of various departments during the complex repair of the land plot. This will improve the living standards of the population, increase the profitability of public utilities, reduce the growth of tariffs for utilities, raise the energy efficiency of the economy as a whole, reduce the cost of capital repairs of buildings and street engineering networks, increase the investment attractiveness of municipalities and will not require large investment costs [4]. Thanks to the complexity of the renovation carried out in Moscow, the living standards of the population in the selected areas can qualitatively raise.

For the successful implementation of a project for the renovation of street engineering networks, the most promising is the use of BIM (Building Information Modeling) information modeling of buildings, structures and infrastructure, in which a $3 \mathrm{D}$ model is built, where each object is connected with a single information database, and interdependent attributes are assigned. Initially, the system was developed for the design and visualization of unique, complex buildings by one organization, now BIM is a process of collective creation and use of information about a building, which forms the basis for all decisions throughout the life cycle of an object. The basis of BIM is the processes, methods and tools for working together with information about the construction object. It allows bringing the level of communication to a qualitatively new level, and due to the creation of a digital model, it best meets the requirements of creating "Smart Cities". A set of BIM tools should help all participants in the process of creating a construction object to effectively interact throughout the entire life cycle of the object, and most importantly, to unambiguously and accurately reproduce the object and receive the necessary information [5].

The effectiveness of BIM implementation is confirmed not only by its mass adoption (70\% was the level of BIM implementation in the UK in 2019 according to the UK National BIM Report), but also by excellent economic results $(90 \%$ of companies achieve a 
positive return from BIM implementation, $50 \%$ of companies declare ROI more than $25 \%$ with a high depth of BIM implementation, and $65 \%$ and $11 \%$, respectively, with a low depth of penetration) [6].

The basic principles of BIM, formulated by Robert Eisch in 1986, began to be implemented in the USA in 2003. Somewhat later, Europe and Asia joined the States in 2007 [7]. Now various software vendors offer the possibility of 4D (+ time, construction schedule), 5D (+ cost, estimate), 6D (+ life cycle, specification, sensors) modeling. We believe that the most appropriate term for " $3+$ " D-modeling (static information model with processes added to it) is - Digital Twin with different levels of informatization. Although, the term has not yet settled down and does not have a clear definition, it is it who best reflects our vision of a "smart utility network" in a "smart city". At the Year In Infrastructure 2019 worldwide project competition conducted by Bentley Systems, one of the BIM software vendors, awards were given not only for the design of buildings and structures, but also for infrastructure projects. The awards were given for: "Improving urban planning with digital twins", complex digital twins of roads and complex digital twins of water networks, "Increasing resiliency of infrastructure with digital twins"; as well as special nominations: "Communication and utilities", "Digital cities", "Modeling reality", "Roads and highways", "Water treatment plants and wastewater treatment plants", and "Water supply, water treatment and drainage networks". The geography of the winners is quite wide. The rest of the main manufacturers of BIM design software have their own awards and winners. All this shows how wide and diverse are the possibilities of modern BIM technologies for the design of utility networks, and the more complex the project, the greater economic efficiency is achieved.

In world practice, there is already some experience in creating street utility networks based on BIM. Mignone, G. proposed the abbreviation BIM-based construction networks $(\mathrm{BbCN})$ [8] - building networks based on BIM, and also described the positive results of their application. Developed nations have long appreciated the benefits of BbCN, in particular, Regional San in Sacramento County, California, launched the EchoWater Project with a budget of $\$ 1.5-2.1$ billion, which involves the modernization of a wastewater treatment system that meets all environmental requirements by 2023.

Despite its obvious advantages, BIM also has obstacles. The most comprehensive assessment of barriers to the use of BIM technologies was carried out by Mehran Oraee et al. They divided all barriers to implementation into 5 groups: "Process", "Actor", "Context", "Team", "Task" [9], and them, in turn, into subgroups, noting that since 2017, the number of issues raised has increased dramatically due to a deeper understanding of communication problems in implementation of $\mathrm{BbCN}$ projects. The most difficult of them now are "Process" barriers, problems of interaction and information exchange using BIM tools and software at all stages of the life cycle. A big problem is the lack of compatibility of various existing tools for developing information models of engineering networks, they have different manufacturers, their own internal methods of data storage, different graphics cores and various commercial data formats for representing files of information models [10]. There are three basic approaches to solving this problem:

1. Creation of a single universal format for data presentation (all software manufacturers must agree);

2. The use of "intermediaries" - programs are transferred into one of five neutral open data formats (the most common - ifc);

3. API (application programming interface) - a set of methods for direct data transfer between different CAD systems (without intermediaries).

Losev K.Yu. substantiates the effectiveness of direct seamless integration of computeraided design (CAD) based on the "web-integration" approach using API, which will be in demand in industrial clusters [11]. This approach will also be useful in densely populated 
areas of the city, where the density of underground communications is high. Creation of "Digital Twins" of the cities and their street engineering networks with access to it through "web-integration" using API will significantly increase the level of coordination in the renovation of street engineering networks.

When BIM is introduced at the design stage without understanding how the resulting model will be used in further stages of the life cycle, most of the benefits are lost, and BIM becomes a burden for the developer and the municipality, and not a means of increasing efficiency. The results of a fairly extensive survey on the use of BIM during the life cycle showed that more than $70 \%$ of participants do not submit a model for operation [12]. The problem of integrating a single digital model at all stages of the life cycle is discussed in [13]. Integral research and production company sees one of the main keys to coordination between participants and data integration in specialized cloud services.

\section{Results}

The desire of the Russian Federation, relying on the positive experience of the developed countries of the world, to manage the urban environment through the creation of "Smart Cities" creates an excellent basis for the use of innovative approaches to the renovation of engineering infrastructure.

Analysis of existing trends in the design and construction of large street engineering networks allows concluding that BIM will be the basis for this. A great advantage of this technology is the ability to solve the main communication problems during the renovation of street engineering networks between all interested parties. Each of them will see not only their networks, but also neighboring ones, which minimizes problems at the stages of approval and construction. BIM allows each participant in the design to complete their part of the project and have access to information about the building, which forms the fundamental basis for all decisions throughout the life cycle of the object [14]. Also, networks created with the help of BIM will significantly reduce costs at the operation stage, since the entire life cycle is calculated at once during design, and the project with its minimum cost is accepted.

We consider it necessary to introduce the term of BIM-based renovation of street engineering networks (BbRSEN) - renovation of street engineering networks based on BIM to denote the process of obtaining "smart" street engineering networks that have gone through renovation based on BIM technologies and reflecting an innovative approach to restoration street engineering network of cities.

BbRSEN allows getting a new engineering network under management, in which each object "knows who it is". For example, a gas pipeline "knows" that it is a gas pipeline, "knows" the material from which it is made, its diameter, depth, as well as the date of upcoming current and major repairs and other necessary information. Using the created model, it will be possible to physically see the minimum distances from one pipe to the remaining underground utilities and structures (including vertical), which facilitates communication and design between all participants in the integrated design of the city's land plot chosen for the renovation.

Despite the fact that the Ministry of Construction of the Russian Federation connects the regional authorities to the development of BIM technologies in Russia and recommends the constituent entities of the Russian Federation to create centers of competence in BIM, we believe that the pace of implementation is quite slow and requires intensification.

It is necessary to change the approach to the restoration of worn out engineering networks. All engineering networks should be considered (designed) at all stages of the life cycle as a single complex of urban infrastructure facilities and, despite the many owners of 
underground communications and land plots, be coordinated and managed from a single center in order to create comfortable living conditions for the population.

The role of the state in this innovative approach should be to create a legal and technical field for organizing work with a digital model created by means of BbRSEN, prepare a regulatory framework, define the terminology (create a construction information classifier), requirements and create a national information platform for the life cycle of urban infrastructure to work with them and an integrated automated information system for urban planning activities (ISUPA). The first attempts in this direction and the launch of the first stage of the seamless urban planning process were planned for 2020 .

Only with standardization it is possible to effectively use BIM, create a digital model through BbRSEN and manage it throughout all stages of the life cycle. Despite the cancellation of the adopted fundamental standards in the field of BIM in the Russian Federation (GOST R 58439.1-2019 and GOST R 58439.2-2019), the process of BIM implementation continues.

Due to the emerging difficulties, it is advisable to launch BbRSEN pilot projects in cities under the $60+$ program using the construction information classifier, which will allow testing developments, identifying emerging problems, primarily in technologies and communication problems between participants, as well as standardizing elements of digital information model, highlight the most important attributes for each of the types of underground communications.

It is also necessary to decide on the operator of the State ISUPA of the Russian Federation, which will be obliged to ensure the proper storage of the received data (digital models), the possibility of prompt exchange of information through the available online space between all interested parties. Figure 1 is a schematic diagram of a digital data environment in which an effective BbRSEN is possible.

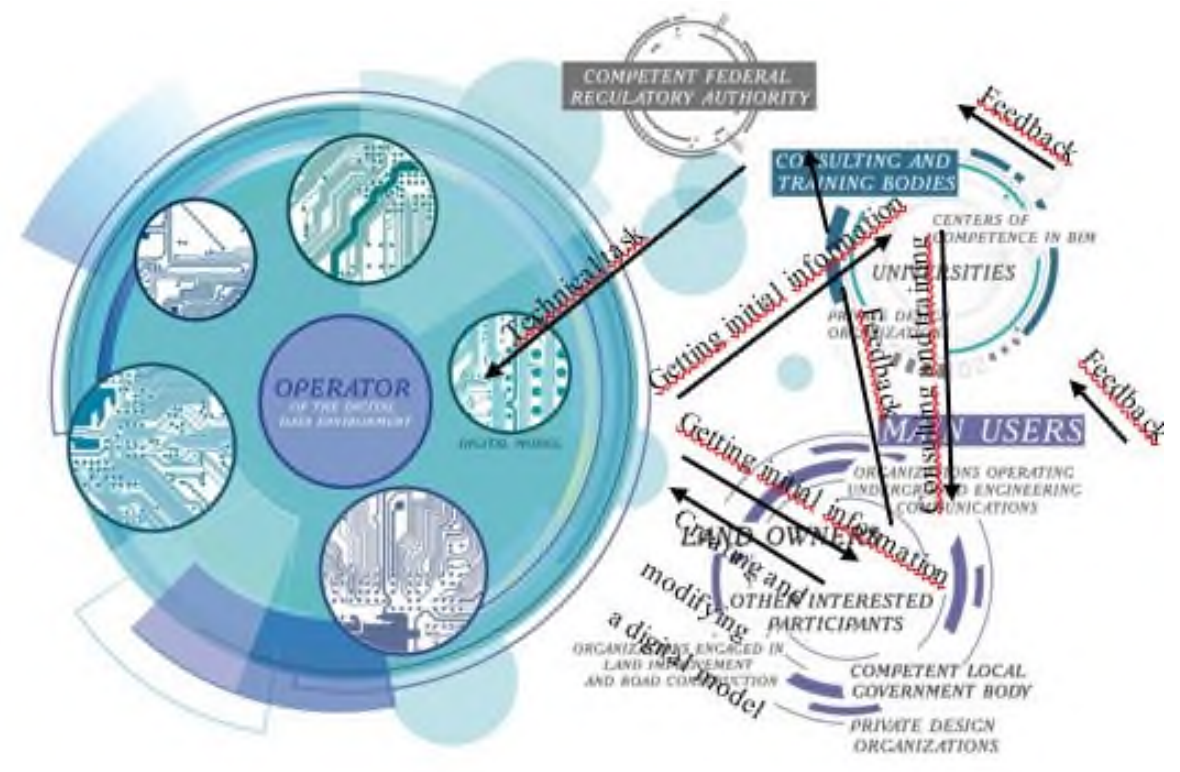

Fig. 1. Diagram of the digital data environment BbRSEN

The responsibility for coordinating the efforts of all organizations operating underground engineering networks (OOUEN) should fall on the shoulders of the city authorities and its competent authorities. It is the municipalities that must find all OOUEN and receive from them a digital model of the city's engineering networks with the most 
important attributes. For the purposes of BbRSEN, information is needed on the state of communications and the planned timing (intervals) of their repair associated with earthworks. The obtained information will allow seeing the regions (clusters) with the most worn-out networks on a digital model in order to prepare for BbRSEN.

To carry out the work on BbRSEN, the main initiator (local authorities) must, in favorable conditions created by the state, stage by stage prepare for their implementation. Figure 2 shows the main stages of work on the initiation and implementation of BbRSEN with the subsequent possibility of looping the work being done on other selected clusters.

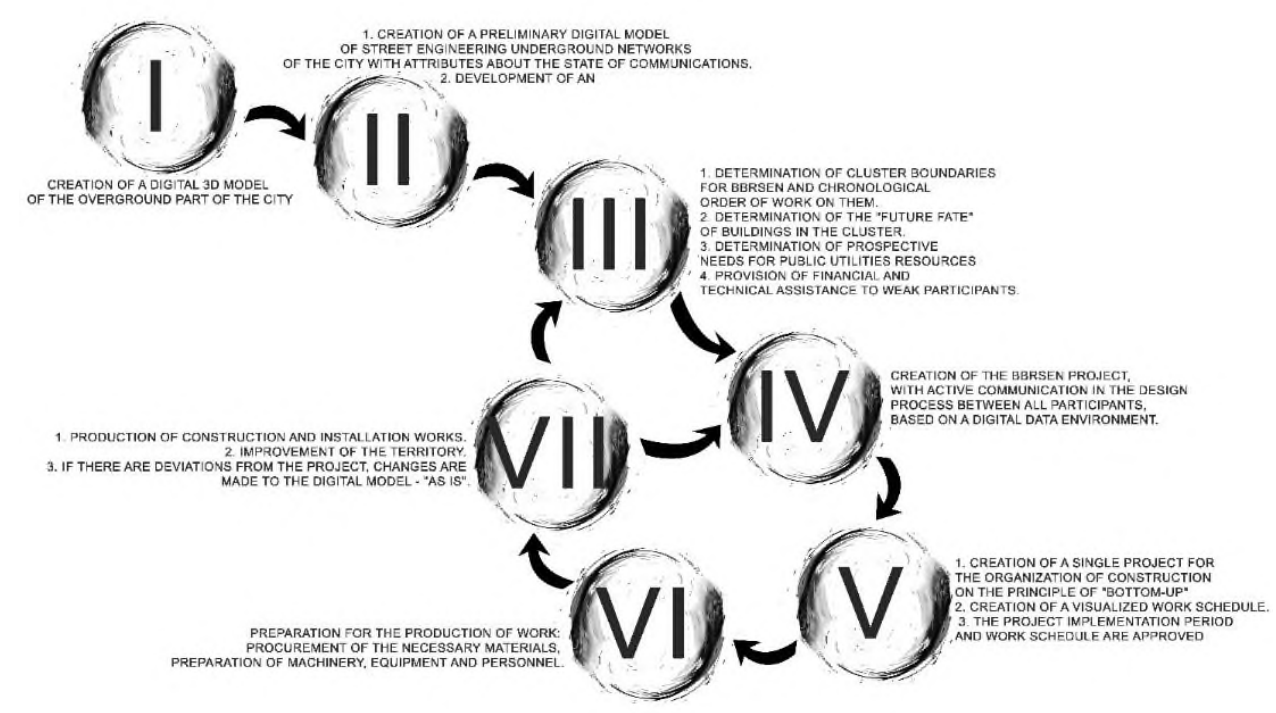

Fig. 2. Stages of work on initiation and implementation of BbRSEN

First stage. Create a digital three-dimensional model of the above-ground part of the city using geographic information systems (3D GIS) and upload it into a single digital data environment. It will become the starting point for the formation of its underground component. Enter the public cadastral map of the city into a digital model, upload data on each land plot. Enter data on the condition of hard road surfaces.

Second stage. Creation of a preliminary (simplified) digital model of street engineering underground networks of the city based on the connection of the information provided from all OOUEN with the obligatory attributes about the state of communications and the planned timing of their repairs associated with earthworks. Now there is no single source of information where one could see the real picture of the wear of the existing engineering networks of the city, divided by quarters. In parallel, it is necessary to develop an architectural design for the appearance of the city after the renovation, to design the aboveground level of the city using modern approaches to the formation of the urban environment.

Third stage. Gathering of the working group, which must determine the boundaries of the clusters on which the BbRSEN will be carried out (this choice must be carried out based on the existing scheme of laying networks, the location of roads and other significant conditions), establish a chronological order of work on them. It is also necessary to provide for the possibility of financial and technical assistance to those OOUEN who cannot independently carry out such large-scale work. It is necessary to help OOUEN to find technical possibilities for planning work using BIM technologies (trained specialists, software, specialized design organizations). The working group should include participants 
who develop a concept for the development of the territory and an architectural project to determine the restrictions imposed on the final product. The buildings in the cluster are determined, in which major repairs will be carried out in parallel with the replacement of engineering networks, or they will be demolished, and new buildings and structures will be built in their place. The prospective needs for the satisfaction with public utilities, the volume of consumed gas, water, heat, electricity, etc. are determined.

Fourth stage. Creation of the BbRSEN project. It is at this stage that all the possibilities that BIM provide for the rapid exchange of information through the online space of the digital environment are fully revealed. Each OOUEN will be able to obtain the maximum total economic effect of the object's life cycle through the use of the latest scientific achievements, lay the networks as required by modern realities, and not use what was laid down more than 40 years ago. OOUEN can see all designed networks online, which will reduce the likelihood of collisions. BIM reduces the time for making changes to the project more than 10 times in the event of collisions, and approvals will be a formality, since even during the design, all the restrictions imposed by neighboring communications are visible. Even at the design stage, land plots can be identified, the laying of communications on which may be difficult or impossible. To solve this problem, it is proposed to establish the possibility of placing linear objects on the terms of a public easement, which is based on the analysis of regulation systems for the placement of engineering structures in foreign countries, where an advantage is given when placing socially significant linear structures [15]. But this is only a draft law. In the event of violations, any department will be able to promptly send instructions to eliminate violations even before the completion of the design, which was previously impossible.

Fifth stage. In fact, this is a continuation of stage 4, but we highlight it because of its importance for the city's population. At this stage, a unified construction organization project and a work schedule are created. BIM allows creating three-dimensional models taking into account the time factor. Each OOUEN sees what it should do on each day of the work. This allows all participants to be coordinated, everyone knows when and what needs to be done. Visualization allows almost completely eliminating the possibility of collisions, and the contractor will be able to repeatedly "scroll through" all the work being done long before the work is done, to identify bottlenecks that can disrupt the work schedule. It also reduces the likelihood of conflicts between contractors related to the delivery of building materials, movement of equipment and manpower, storage sites for material and soil. Taking into account the specifics of the location of the pipelines, all work must be planned and carried out "from the bottom up". First, the pipes with the greatest depth are laid, then the overlying ones. Visualization will help to eliminate errors in this process. After approvals and elimination of conflicts, the project implementation period is designed (the date of its start and completion), and the work schedule is approved.

Sixth stage. The stage of preparation for the production of work, the purchase of the necessary materials, devices and other necessary resources. Each OOUEN itself seeks the necessary resources, but BIM technology allows creating a detailed specification of everything that is needed, with a high degree of automation and a low chance of errors.

Seventh stage. Construction and installation works. BbRSEN will reduce the probability of error to a minimum at the stages of project implementation, will significantly increase the speed and quality of work, and will significantly reduce the time during which residents will have to experience inconvenience. If it is necessary to deviate from the project during the production of work, they are entered into the digital model "as is" and are immediately visible to all other participants. The stage ends with the improvement of the territory.

In addition to OOUEN, organizations engaged in the improvement of the territory (roads, sidewalks, green spaces, small architectural forms, etc.) should actively participate in BbRSEN. In the digital model, they also create their part, starting from the work 
performed by OOUEN. An obligatory attribute of the created digital model of the accomplished improvement should be data on the life cycle, the timing of its repairs in order to harmonize the timing of the repairs of road surfaces and underground communications under them, thereby creating comfortable living conditions for the population and reducing costs of operation for municipalities and OOUEN. Thanks to the transition to "lean production" and BbRSEN, it is possible to reduce the rate of growth in utility tariffs for the population.

\section{Discussion and Conclusions}

Modern trends in the global construction industry show an increasing digitalization and the transition to BIM. The Russian Federation is significantly behind in the implementation of BIM not only in the construction of street engineering networks, but also in the construction of buildings in general, and this should become a challenge that must be accepted! It is necessary to introduce BIM more intensively, primarily for BIM-based renovation of street engineering networks. Since in the construction of large buildings, the owners will independently come to the use of BIM due to its cost-effectiveness, the state should push for this for street infrastructure, creating a favorable legal and technical environment.

Our work shows that:

1. The introduced term of BIM-based renovation of street engineering networks (BbRSEN) most fully reflects the most promising and economical approach to the renovation of the street engineering network of large cities in the context of the creation of "Smart cities" and the transition to the operation of housing and communal services based on life cycles.

2. The extremely low involvement of Russian companies (5-7\%) in the use of BIM, the lack of interest of the regional and municipal authorities in the development of information modeling technologies, and the small number of professional personnel working with BIM create obstacles to the implementation of smart cities and the transition to lean production. This is caused, first of all, by a low awareness of BIM capabilities, including communicative ones. It is necessary to create BIM competence centers in all regions of the country, as well as stimulate the introduction of a master's program in universities, which will reduce the shortage of professional personnel in the BIM industry in the near future.

3. Despite the difficulties in creating the regulatory framework, the federal authorities should create a digital data environment with uniform standards and environmental rules in the near future. Given the high rate of development of BIM technologies, this environment should be flexible and open enough, have a convenient online interface, provide an opportunity to work in it using software from various manufacturers, and all data should be securely stored with protection from hacker attacks and unintentional loss of information, while having a high enough power for many design teams to work at once, on several digital models simultaneously. It is necessary to choose a reliable Operator of the digital data environment which will be able to create all this and economically operate it. The proposed digital environment will become the main platform for BbRSEN and for the creation of a digital model and a communication channel for interested parties.

4. The proposed step-by-step procedure for the implementation of BbRSEN in large cities is quite universal and suitable for any city. The created cyclicality allows BbRSEN to be carried out in turn on each dedicated cluster, creating an innovative opportunity for communication of all interested parties at a qualitatively new level. This procedure 
allows the creation of "Smart grids" that can become the basis for the future development of a "Smart city", because high-quality infrastructure raises the standard of living of the population and creates a favorable investment climate in the region. This procedure will allow each participant to effectively prepare for large-scale work and gradually coordinate their actions with each other, create a visualization of the entire volume of parallel work throughout their production, thereby eliminating collisions and overlaps in the process of construction and installation work.

5. When creating smart grids based on BIM, it is necessary to include a mandatory attribute characterizing the timing of planned works associated with earthworks. When carrying out BbRSEN, it is necessary to oblige the organization that performs the improvement of the cluster, first of all, the hard surface of the roads, to perform work based on BIM, with an attribute containing information on the timing and frequency of planned repairs associated with the opening of the upper hard surface. Harmonization of the frequency of repair work on underground utilities and hard pavement above it will significantly reduce costs (primarily for the subsequent improvement of the territory), as well as improve the quality of life of the population of cities by reducing the duration of repair work on the site, reducing the growth of utility rates, and improving the quality of landscaping.

6. BbRSEN is carried out with the involvement of budgetary funds, and the calculation of the estimated cost is mandatory (Article 8.3 of the Civil Code of the Russian Federation). The accuracy of the calculation, thanks to the use of BIM, will be quite high, which will not allow the implementation to go beyond the budget and will solve the serious problem of large infrastructure projects.

\section{References}

1. M. I. Alekseev, L. A. Baranov, YU. A. Ermolin, Priblizhennaya analiticheskaya ocenka pokazatelej nadezhnosti stareyushchih obektov VKKH Voda i ekologiya: problemy i resheniya, 3(79), 3-8 (2019)

2. E. V. Popov, K. A. Semyachkov, Sistematizaciya podhodov k ocenke razvitiya umnyh gorodov, Ekonomika regiona, 16(1), 14-27 (2020)

3. P. V. Shatalov, Justification of the effectiveness of renovation of the gas pipeline system on an innovative basis. Journal of Economy and entrepreneurship, 13(11), 845849 (Moscow, 2019)

4. P. Shatalov et al., Economic Effect of the Renovation of Street Engineering Networks International Scientific Conference Energy Management of Municipal Facilities and Sustainable Energy Technologies EMMFT 2019

5. T. S. Golosova, "Problemy importozameshcheniya $\mathrm{v}$ oblasti informacionnogo modelirovaniya (BIM)" ETAP: ekonomicheskaya teoriya, analiz, praktika, 2, 127-133 (2017)

6. McGraw Hill Construction Research \& Analytics, The Business Value of BIM for Construction in Major Global Markets: How Costractors around the World Are Driving Innovation With BIM. SmartMarket Report 64 (2014)

7. V. V. Sharmanov, A. E. Mamaev, A. S. Bolejko, Yu. S. Zolotova, Trudnosti poetapnogo vnedreniya BIM, Stroitel'stvo unikal'nyh zdanij i sooruzhenij, 10, 109 (2015)

8. G. Mignone, M. R. Hosseini, N. Chileshe, M. Arashpour, Enhancing collaboration in BIM-based construction networks through organisational discontinuity theory: a case 
study of the new Royal Adelaide Hospital, Arch. Eng. Design Manag, 12, 333-352 (2016)

9. M. Oraee, et al., Collaboration barriers in BIM-based construction networks: A conceptual model, International Journal of Project Management, 37(6), 839-854 (2019)

10. O. Grishko, Upravlenie proektnoj organizaciej - pyat' zadach dlya Pilot-ICE, SAPR i Grafika, 2, 2-4 (2017)

11. K. Yu. Losev, The approach to CDE design information support within a construction object life cycle. The Eurasian Scientific Journal, 6(10) (2018)

12. R. Eadie, M. Browne, H. Odeyinka, C. McKeown, S. McNiff, BIM implementation throughout the UK construction project lifecycle: An analysis. Automation in Construction, 36, 145-151 (2013)

13. X. Xu, L. Ma, L. Ding, A Framework for BIM-enabled Life-cycle Information Management of Construction Project. International Journal of Advanced Robotic Systems, 11, 13 (2014)

14. A. E. Perceva, A. A. Volkova, N. S. Hizhnyak, N. S. Astaf'eva, "Osobennosti vnedreniya BIM-tekhnologii v otechestvennye organizacii" Vestnik evrazijskoj nauki, 9, 6(43), 51 (2017)

15. V. K. Popov, K. V. Studenova, M. V. Kozina, "Voprosy planirovaniya i formirovaniya inzhenernoj infrastruktury na territorii $\mathrm{g}$. Tomska $\mathrm{v}$ usloviyah reformirovaniya zemel'nogo zakonodatel'stva" Izvestiya Tomskogo politekhnicheskogo universiteta. Inzhiniring georesursov, 329(5), 99-107 (2018) 